\title{
Spectroscopic studies of Er3+-Yb3+ codoped multicomposition tellurite oxide glass
}

\begin{abstract}
Multicomposition of $\mathrm{Er}^{3+}-\mathrm{Yb}^{3+}$ codoped tellurite oxide, $\mathrm{TeO}_{2}-\mathrm{ZnO}-\mathrm{PbO}-\mathrm{TiO}_{2}-\mathrm{Na}_{2} \mathrm{O}$ glass has been investigated. Detailed spectroscopic study of the Judd-Ofelt analysis has been performed from the measured absorption spectrum in order to obtain the intensity parameters $\Omega_{\mathrm{t}}(\mathrm{t}=2,4,6)$. The calculated $\Omega_{\mathrm{t}}$ values were then utilized in the determination of transition probabilities, radiative lifetimes and branching ratios of the $\mathrm{Er}^{3+}$ transitions between the $J$ (upper)-J(lower) manifolds. Both visible upconversion and near-infrared spectra were characterized under the $980 \mathrm{~nm}$ laser diode excitation at room temperature.
\end{abstract}

Keyword: Judd-Ofelt analysis; Tellurite oxide glass; Upconversion 